\title{
Evidence of the differentiated structural arrangement of constitutive heterochromatin between two populations of Astyanax scabripinnis (Pisces, Characidae)
}

\author{
Monique Mantovani, Luciano Douglas dos Santos Abel, Carlos Alberto Mestriner \\ and Orlando Moreira-Filho \\ Universidade Federal de São Carlos, Departamento de Genética e Evolução, São Carlos, SP, Brazil.
}

\begin{abstract}
The composition of heterochromatin classes along the chromosomes of specimens from two populations of the fish Astyanax scabripinnis was examined using fluorescence banding with GC- and AT-DNA specific fluorochromes and fluorescence in situ hybridization (FISH) with an AT-rich satellite DNA (As51) probe. For the pericentromeric heterochromatin blocks neither GC/AT-DNA specific fluorochromes nor the FISH technique produce any response with chromosomes from either of the populations. On the other hand, the telomeric distal heterochromatin blocks of both populations fluoresced when the FISH technique was applied but showed distinct responses after GC-specific fluorochrome treatments, leading us to propose different structural arrangements of the FISH-positive heterochromatins. Such differences in chromosome banding patterns together with other karyotypic differences suggest differentiation of these populations at taxonomic level.
\end{abstract}

Key words: satellite DNA, chromosome structure, base-specific fluorochromes, heterochromatin heterogeneity, fluorescence in situ hybridization

Received: July 15, 2003; Accepted: February 16, 2004.

\section{Introduction}

The constitutive heterochromatin of fishes is usually studied by C-banding to characterize distinct patterns of heterochromatin distribution in karyotypes. Comparative analyses of these patterns have lead to a greater understanding of the genetic and evolutionary relationships within and between different groups and have contributed significantly to cytotaxonomic studies (Garcia et al., 1987; Galetti Jr. et al., 1991; Almeida-Toledo et al., 1996). However, because the composition of constitutive heterochromatin may vary and C-banding does not reveal the content of nitrogenous bases, other techniques are required (see Verma, 1988; Sumner, 1990). Base-specific fluorochromes were initially used to identify adenine/thymine (AT)- or guanine/cytosine (GC)-rich heterochromatin portions (Schweizer, 1976; Schmid, 1980). This led to substantial advances in the analysis of the constitutive heterochromatin of fishes, allowing for the identification of different heterochromatin classes (Mayr et al., 1988; Caputo et al., 1997; Molina et al., 1998; Artoni and Bertollo, 1999;

Send correspondence to Orlando Moreira-Filho. Universidade Federal de São Carlos, Departamento de Genética e Evolução, Rodovia Washington Luís km 235, Caixa Postal 676, 13565-905 São Carlos, SP, Brazil. E-mail: omfilho@ power.ufscar.br.
Artoni et al., 1999; Margarido and Galetti Jr., 2000; Sola and Gornung, 2001).

Nevertheless, it has been shown that longitudinal Qand R-bands result from differential folding paths of sequences associated with the chromosome scaffold (SARs), leading to the assumption that positive or negative fluorochrome responses are dependent not only on the base composition of the DNA but also on the arrangement of the bases in the chromosomal structure (Saitoh and Laemmli, 1994). Hence, it is through isolation, sequencing and in situ location of satellite DNA that chromosome heterochromatic regions can really be characterized (Haaf et al., 1993; Reed and Phillips, 1995; Garrido-Ramos et al., 1994; 1995; 1998; Oliveira and Wright, 1998; Mestriner et al., 2000; Phillips and Reed, 2000).

Owing to its high morphologic and karyotypic diversity, Astyanax scabripinnis has been considered a complex of species (Moreira-Filho and Bertollo, 1991). Constitutive heterochromatin has been involved in the chromosomal differentiation of several A. scabripinnis populations (Moreira-Filho and Bertollo, 1991; Maistro et al., 1998; Mizoguchi and Martins-Santos, 1998; Maistro et al., 2000; Mantovani et al., 2000) and fluorescent staining has already revealed constitutive heterochromatin heterogeneity in one population (Souza et al., 1996). 
In one $A$. scabripinnis population a 51 bp (59\% AT) satellite DNA called As51 has been cloned and sequenced and its chromosomic position found to be in the noncentromeric heterochromatin, i.e. the distal blocks of acrocentric chromosomes, the nucleolus organizer regions (NORs) and the supernumerary chromosome (Mestriner et al., 2000).

The purpose of our work was to use the fluorescence in situ hybridization (FISH) technique to locate this repetitive DNA in the chromosomes of other A. scabripinnis populations and to carry out base-specific fluorochrome analyses which would allow us to evaluate the factors involved in fluorochrome staining based on homology between As51 and the heterochromatic regions. In addition, such data may shed light on the heterogeneity of heterochromatin and on the cytotaxonomic relationships within this species complex.

\section{Materials and Methods}

\section{Specimens}

We collected specimens of Astyanax scabripinnis (Pisces, Characiformes, Characidae) from two different Brazilian populations, seven females and three males from the Marrecas stream near the city of Londrina and four females and four males from the Centenário stream near the town of Maringá, both these streams being within the Paranapanema river basin in the state of Paraná.

\section{Chromosome preparations and C-banding}

Mitotic chromosomes were obtained from anterior kidney tissue using the cell suspension technique described by Bertollo et al. (1978). The constitutive heterochromatin was visualized by the C-banding technique of Sumner (1972) and the chromosomes were classified according to the criteria of Levan et al. (1964).

\section{Base-specific fluorochrome staining}

The GC-specific fluorochrome mithramycin A (MM) plus the non-fluorescent counterstain distamycin A (DA) were used according to the method of Schmid (1980) and the AT-specific fluorescent compound 4',6-diamidino-2phenylindole (DAPI) was used with and without DA counterstaining (Schweizer et al., 1978). The DA/MM preparations were stored in the dark for at least 15 days before being exposed to ultraviolet (UV) light through a 450-490 nm filter, while the DAPI and DA/DAPI slides were kept in the dark for $24 \mathrm{~h}$ before exposure to UV light through a 360-390 nm filter. All the preparations were examined using an Olympus BX50 fluorescence microscope and the metaphase photographs taken using Kodak TMAX 100 ISO film.

\section{Fluorescence in situ hybridization (FISH)}

As the probe we used the As51 satellite DNA sequence inserted in a pGEM4 plasmid (Mestriner et al., 2000) labeled with dATP-biotin by nick translation using the BioNick ${ }^{\mathrm{TM}}$ Labeling System (Gibco BRL) according to the manufacturer's instructions.

The FISH technique was carried out according to the method of Pinkel et al. (1986), with some modifications. The chromosomes were denatured in $70 \%(\mathrm{v} / \mathrm{v})$ formamide in $2 \mathrm{x}$ saline sodium citrate $(2 \mathrm{xSSC})$ solution at $70^{\circ} \mathrm{C}$ for $5 \mathrm{~min}$ followed by a further $10 \mathrm{~min}$ denaturation at $100^{\circ} \mathrm{C}$ after which $50 \mu \mathrm{L}$ of hybridization solution (containing $50 \%$ formamide in $2 \mathrm{xSSC}, 10 \%(\mathrm{w} / \mathrm{v})$ dextran sulfate, $200 \mathrm{ng} / \mu \mathrm{L}$ of human placenta DNA and about $125 \mathrm{ng}$ of probe) was applied to each slide under a coverslip. Hybridization was performed for $15 \mathrm{~h}$ at $37^{\circ} \mathrm{C}$ in a moist chamber containing $60 \%(\mathrm{v} / \mathrm{v})$ formamide, after which the slides were rinsed with $50 \%$ formamide in $2 \times \mathrm{SSC}$ at $42{ }^{\circ} \mathrm{C}$ for $20 \mathrm{~min}$ followed by $0.1 \mathrm{xSSC}$ at $60^{\circ} \mathrm{C}$ for $15 \mathrm{~min}$. Detection of the hybridized probe was carried out using three cycles of avidin-fluorescein isothiocyanate (avidin-FITC) and biotinylated anti-avidin (Sigma). The slides were mounted in $25 \mu \mathrm{L}$ of Vectashield antifade (Vector) and the chromosomes stained with $1 \mu \mathrm{L}$ of a $50 \mu \mathrm{g} / \mathrm{mL}$ solution of propidium iodide, the metaphase chromosomes being examined using an Olympus BX50 fluorescence microscope and photographed on Kodak Gold Ultra 400 ISO film.

\section{Results}

The chromosome complement of the A. scabripinnis specimens from the Marrecas population was $2 n=48$ while those from the Centenário population was $2 \mathrm{n}=50$ (Figure 1).

Both populations displayed constitutive heterochromatin in the centromeric region of most chromosomes and heterochromatic blocks (most of them large) in the telomeric regions of the long arms, principally in the subtelocentric and acrocentric chromosomes (Figures 2a and 3a). A numerical and quantitative inter-individual polymorphism was observed in the distribution of the distal heterochromatin (terminal heterochromatic blocks) in some chromosomes of both populations (data not shown).

FISH using the As51 satellite DNA probe showed the homology of this repetitive DNA family with the constitutive heterochromatin revealed by C-banding, except for the pericentromeric heterochromatic blocks (Figures 1, 2a and 3a). This technique also confirmed the polymorphism of the distal heterochromatin (e.g. pair 25, Figure 1b).

The distal heterochromatic blocks of both populations were revealed to be DA/DAPI negative (Figures 2c and 3c) but provide no response when only DAPI was employed (Figures 2 and 3). This chromosomal domain was DA/MM negative in the $2 \mathrm{n}=48$ Marrecas population 


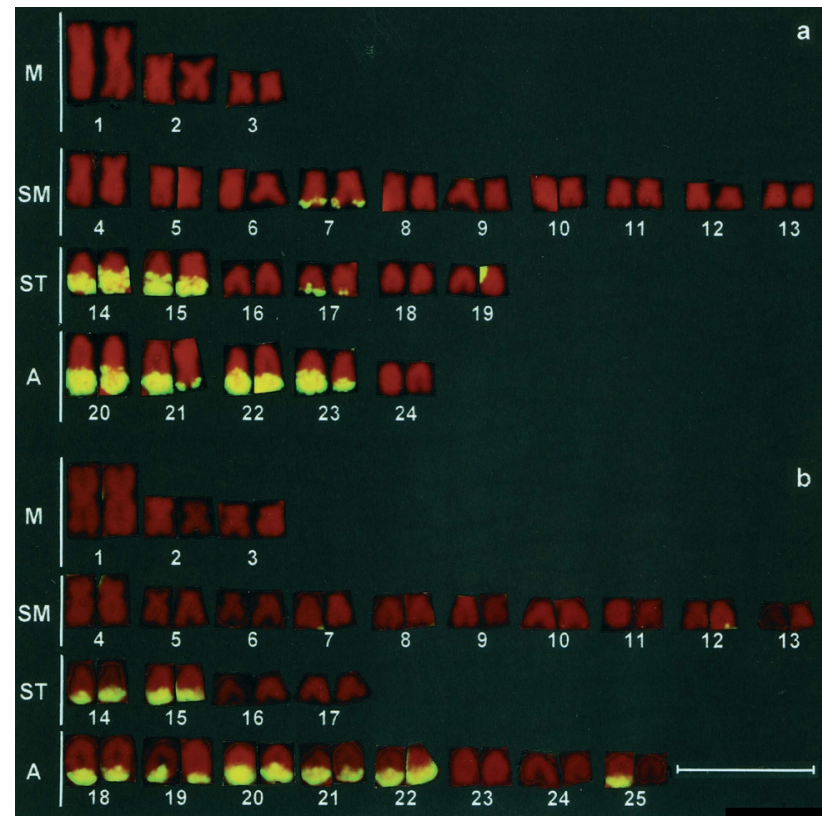

Figure 1 - Karyotypes of Astyanax scabripinnis produced using fluorescence in situ hybridization (FISH) and the As51 satellite DNA as probe. The distribution of this repetitive DNA family is restricted to the distal region, mainly of the subtelocentric and acrocentric chromosomes. (a) $2 \mathrm{n}=48$ specimen from the Marrecas population (Londrina, Paraná), (b) $2 \mathrm{n}=50$ specimen from the Centenário population (Maringá, PR). $\mathrm{M}=$ metacentric, $\mathrm{SM}=$ submetacentric, $\mathrm{ST}=$ subtelocentric and $\mathrm{A}=$ acrocentric. Bar $=5 \mu \mathrm{m}$.

(Figure $2 \mathrm{~b}$ ) and DA/MM positive in the $2 \mathrm{n}=50$ Centenário population (Figure $3 b$ ).

The pericentromeric heterochromatins of the two populations did not respond to the $\mathrm{GC}$ and $\mathrm{AT}$ fluorochrome ligand treatments (Figures $2 b-d$ and $3 b-d$ ).

\section{Discussion}

The karyotypes and fundamental numbers of $A$. scabripinnis from the Marrecas and Centenário stream populations agree with the results of Moreira-Filho and Bertollo (1991) and Mantovani et al. (2000). The distribution and polymorphism of the constitutive heterochromatin observed here were described and extensively discussed by Mantovani et al. (2000).

A comparison between the $\mathrm{C}$-banding pattern and our FISH results enabled us to distinguish at least two groups of constitutive heterochromatin: i) pericentromeric heterochromatin, which showed no homology with the As51 repetitive DNA family and ii) a set of distal heterochromatins which were homologous with the As51 sequence.

These data provide evidence of the particular homogeneity of each heterochromatin chromosomal domain (distal and pericentromeric) and of the heterogeneity between these two domains. Both the homogeneity and the heterogeneity are related to the equilocal distribution of heterochromatic regions between members of the complement (John, 1988). According to the "bouquet" polariza- tion model, the physical contact of equilocal heterochromatic DNA of homologues and non-homologues is provided by the spatial disposition of chromosomes in the nucleus during the initial stages of meiosis when molecular processes favor the homogenization of satellite DNA sequences (Schweizer and Loidl, 1987).

According to Mantovani et al. (2000), both the populations analyzed by us show equilocal heterochromatin distribution, and it may be that the above results derive from this distribution.

A similar lack of response of the pericentromeric heterochromatic domain after base-specific fluorochrome staining as that observed in the two populations studied by us has also been found in the chromosomes of other fish species (Sola et al., 1992; Rossi et al., 1996; Sola et al., 2000) and of other A. scabripinnis populations (Souza and Moreira-Filho, 1995; Souza et al., 1996). Considering the common pattern displayed by the A. scabripinnis populations studied to date, it may be that pericentromeric heterochromatins contain sequences with preserved compositions (seen in several species of the family Sparidae, see Garrido-Ramos et al., 1995) and preserved structures, since pericentromeric heterochromatin plays a fundamental role in the centromeric structure (Haaf et al., 1992).

In contrast, the distal heterochromatic domains of both populations were DA/DAPI negative and showed no response to DAPI staining, which seems at variance with the presence of the AT-rich As51 satellite DNA in the distal heterochromatins. However, the presence of DA/DAPI negative bands may agree with the base-pair composition of this heterochromatic domain because distamycin has high affinity with and is specific to AT-rich domains, forming a very stable complex with DNA and causing structural changes in the double strand (Zimmer et al., 1971) which may reduce or block the accessibility of DAPI to the chromosomal DNA, as has been previously described for another A. scabripinnis population (Souza et al., 1996).

Although DAPI is known to bind to both GC and AT base pairs its fluorescence is significantly enhanced by AT-rich regions (Lin et al., 1977) so that the AT base content of the As51 satellite DNA (59\%) may be insufficient to produce DAPI-positive fluorescence, as has already been described for daunomycin, an antibiotic that only fluoresces when bound to highly AT-rich (65\%) DNAs (Comings and Drets, 1976; Comings, 1978; Johnston et al., 1978). Moreover, when discussing other fluorescent compounds, Comings and Drets (1976) pointed out that lack of fluorescence in heterochromatic regions may be due to the effect of chromosomal proteins on access of the fluorochromes to satellite DNA, while Saitoh and Laemmli (1994) stated that the structural organization of the chromosomal heterochromatic sequences may also be a factor in whether or not fluorescence occurs.

As regards the GC-specific fluorochrome staining, the two A. scabripinnis populations showed distinct fluo- 

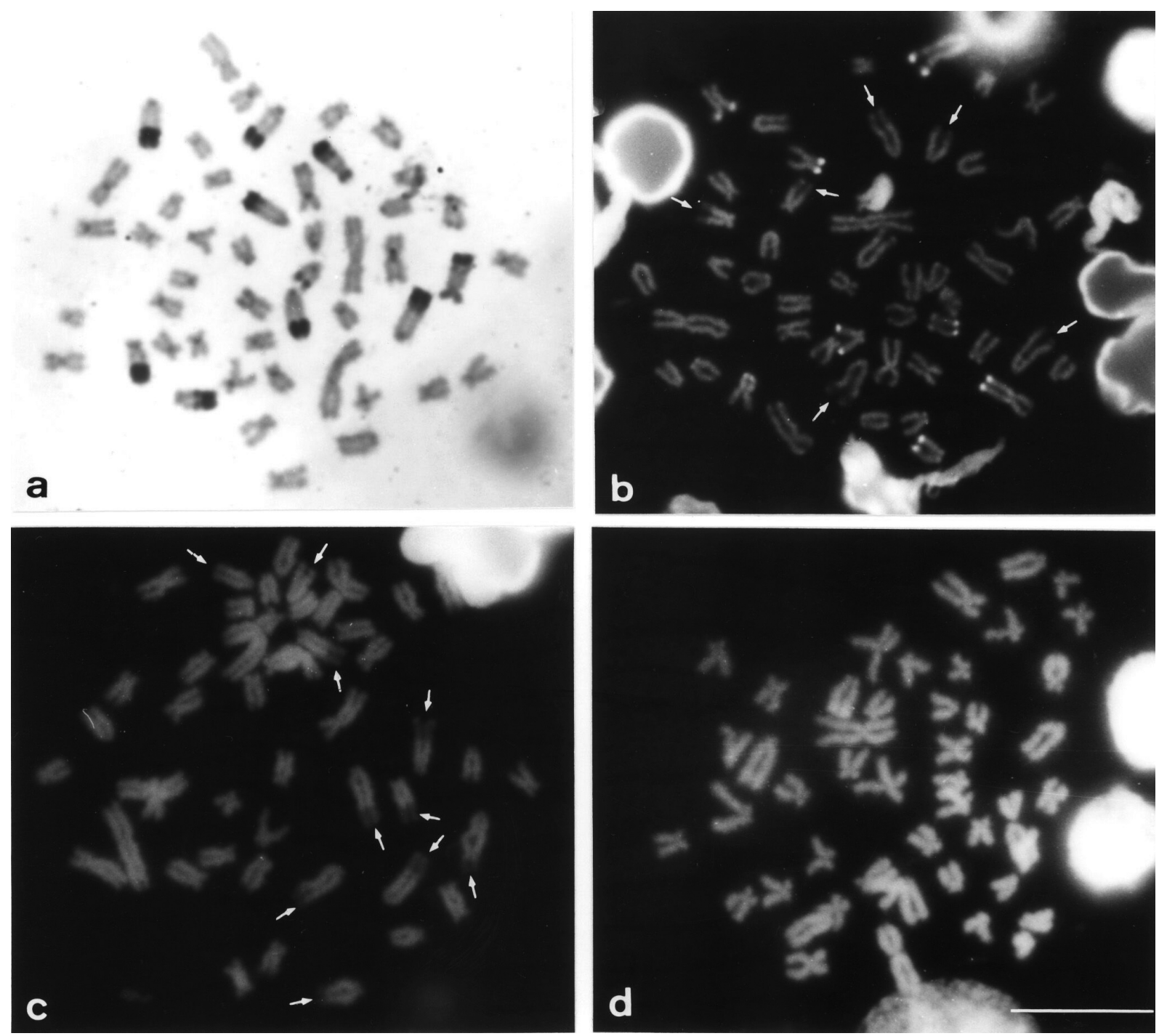

Figure 2 - Metaphase chromosomes of Astyanax scabripinnis from the Marrecas population showing distinct responses to different base-specific fluorochromes. (a) Incomplete C-banded metaphase chromosome showing constitutive heterochromatin (dark regions). The telomeric heterochromatic blocks are indicated by arrows as DA/MM negative in (b) and DA/DAPI negative in (c), while pericentromeric heterochromatin did not respond to these treatments. (d) DAPI treatment showing homogeneous staining of the chromosomes. The DA/MM-positive staining in (b) corresponds to the nucleolus organizer regions. Bar $=5 \mu \mathrm{m}$.

rescent patterns for distal heterochromatins. In the $2 n=48$ Marrecas population the heterochromatin was DA/MM negative, in agreement with the base pair composition of this domain but, in contrast, the distal heterochromatin of the $2 \mathrm{n}=50$ Centenário population was DA/MM positive, which might suggest a higher proportion of GC bases were it not for its homology with the As51 satellite DNA.

Even though the NORs of fishes frequently fluoresce after GC-specific fluorochrome staining (Schmid and Guttenbach, 1988) these regions have been detected associated to the distal heterochromatic blocks in only one chromosome of the Centenário population karyotype (Mantovani et al., 2000), indicating that the DA/MMpositive pattern is resultant from characteristics of the heterochromatin itself.
Since the distal heterochromatic domains of the Marrecas and Centenário populations show homology with the same sequence, as revealed by the FISH-As51 method, the dissimilar responses described above cannot be attributed to base pair composition and our data may be evidence of differentiated structural arrangements of the distal constitutive heterochromatins in the populations studied.

The DA/MM-positive staining of the distal heterochromatin of the $2 n=50$ Centenário population does not exclude the possibility of the presence of a second, GC-rich, satellite DNA family besides the As51 family in the same heterochromatic domain. The GC clusters of this putative family might be exposed on the chromosomes of the Centenário population, while the $2 \mathrm{n}=48$ Marrecas population may possess inverse structural organization that ex- 

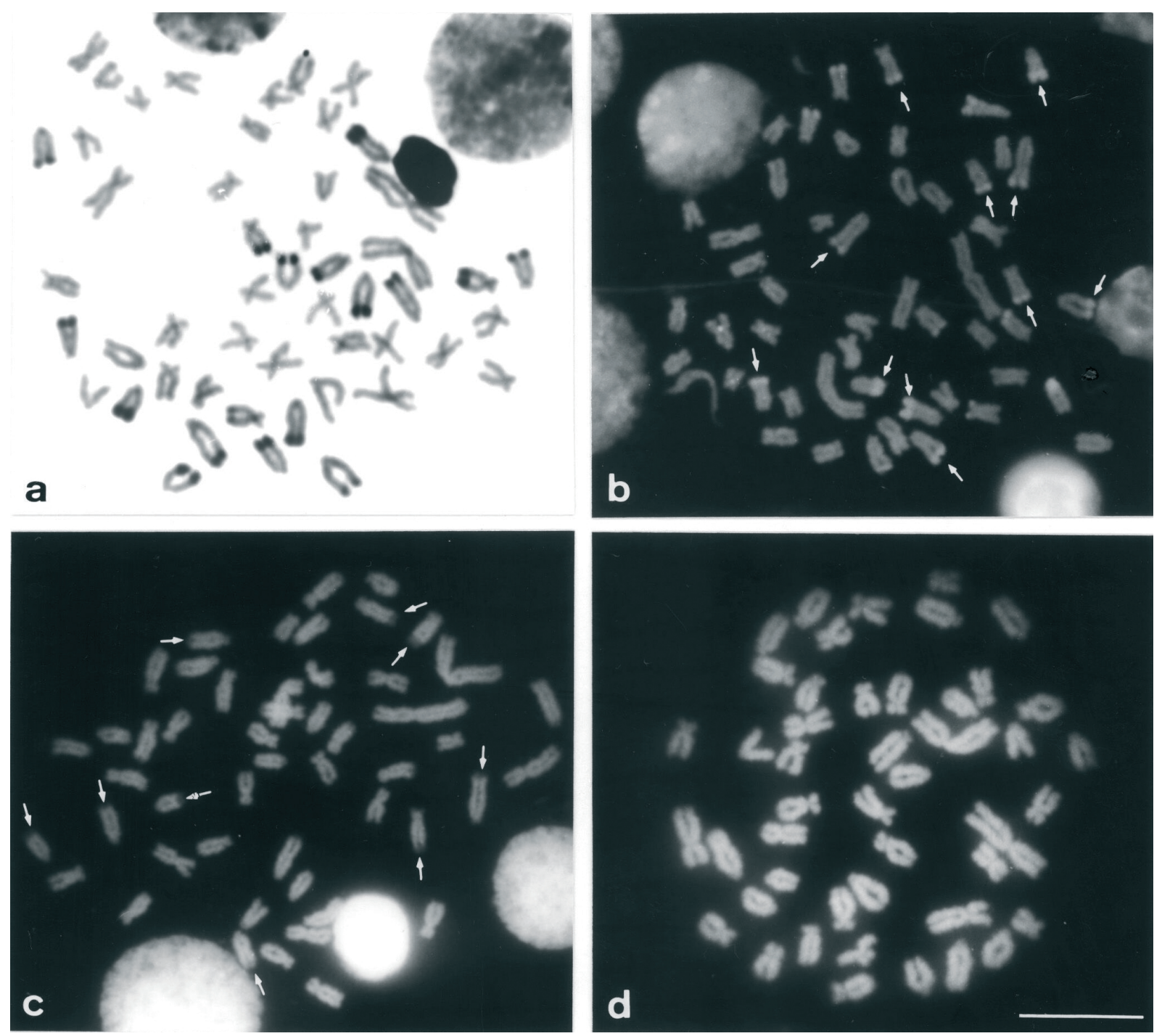

Figure 3 - Metaphase chromosomes of Astyanax scabripinnis from the Centenário population showing distinct responses to different base-specific fluorochromes. (a) C-banding showing constitutive heterochromatin (dark regions). The telomeric heterochromatic blocks are indicated by arrows as DA/MM positive in (b) and DA/DAPI negative in (c), while pericentromeric heterochromatin did not respond to these treatments. In (d) the chromosomes are uniformly stained with DAPI. The DA/MM-positive areas, not indicated by arrows in (b), are nucleolus organizer regions. Bar $=5 \mu \mathrm{m}$.

poses the As51 sequences. These assumptions support the presumed influence of the non-random arrangement of nucleotide sequences based on the fluorescent patterns obtained with specific fluorochromes (Johnston et al., 1978; Saitoh and Laemmli, 1994), and again support the proposition that the distal heterochromatins of the Centenário and Marrecas populations are structurally dissimilar. The presence of a GC-rich satellite sequence in the distal heterochromatin of the Centenário population could be checked using the method of Rab et al. (1996), which employs differential denaturation based on the fact that GC-rich clusters have higher thermal stability.

The DA/MM negative pattern of the distal heterochromatic domain of the $2 n=48$ Marrecas population has also been observed for a $2 n=48$ population of the scabripinnis complex from another river basin (I. L. Souza, personal communication) and therefore appears to be an exclusive characteristic of $2 n=48$ populations studied to date. This indicates that the same structural conformation of heterochromatin is shared by these cytotypes, reinforcing the idea that $2 \mathrm{n}=48 \mathrm{~A}$. scabripinnis populations from different river basins are more closed related to each other than to the $2 \mathrm{n}=50$ populations from the same river basin (Oliveira et al., 1998; Mantovani et al., 2000).

In addition to highlighting the karyotypic diversity of the scabripinnis complex, this work also reveals that a combination of techniques can be valuable in the qualitative investigation of constitutive heterochromatin in fish, since the results allow one to conclude that other factors besides the base composition of DNA may influence the pattern of fluorescence obtained on fluorochrome staining. 


\section{Acknowledgments}

The authors are grateful to Drs. Lúcia Giuliano Caetano and Horácio Ferreira Júlio Júnior for their help in collecting the specimens, and to Drs. Luiz Antonio Carlos Bertollo and Pedro Manoel Galetti Júnior for their valuable suggestions. This work was supported by FAPESP (Fundação de Amparo à Pesquisa do Estado de São Paulo, Brazil) and CNPq (Conselho Nacional de Desenvolvimento Científico e Tecnológico, Brazil).

\section{References}

Almeida-Toledo LF, Bigoni AP, Bernardino G, Foresti F and Toledo-Filho SA (1996) Karyotype and NOR conservatism with heterochromatin reorganization in Neotropical Bryconids. Caryologia 49:35-43.

Artoni RF and Bertollo LAC (1999) Nature and distribution of constitutive heterochromatin in fishes, genus Hypostomus (Loricariidae). Genetica 106:209-214.

Artoni RF, Molina WF, Bertollo LAC and Galetti Jr PM (1999) Heterochromatin analysis in the fish species Liposarcus anisitsi (Siluriformes) and Leporinus elongatus (Characiformes). Genet Mol Biol 22:39-44.

Bertollo LAC, Takahashi CS and Moreira-Filho O (1978) Cytotaxonomic considerations on Hoplias lacerdae (Pisces, Erythrinidae). Brazil J Genet 1:103-120.

Caputo V, Marchegiani F, Sorice M and Olmo E (1997) Heterochromatin heterogeneity and chromosome variability in four species of gobiid fishes (Perciformes: Gobiidae). Cytogenet Cell Genet 79:266-271.

Comings DE (1978) Mechanisms of chromosome banding and implications for chromosome structures. Ann Rev Genet 12:25-46.

Comings DE and Drets ME (1976) Mechanisms of chromosome banding. IX. Are variations in DNA base composition adequate to account for quinacrine, hoechst 33258 and daunomycin banding? Chromosoma 56:199-211.

Galetti Jr PM, Mestriner CA, Venere PC and Foresti F (1991) Heterochromatin and karyotype reorganization in fish of the family Anostomidae (Characiformes). Cytogenet Cell Genet 56:116-121.

Garcia E, Alvarez MC and Thode G (1987) Chromosome relationships in the genus Blennius (Blenniidae, Perciformes). C-banding patterns suggest two karyoevolution pathways. Genetica 72:27-36.

Garrido-Ramos MA, Herrán R, Rejón CR and Rejón MR (1998) A satellite DNA of the Sparidae family (Pisces, Perciformes) associated with telomeric sequences. Cytogenet Cell Genet 83:3-9.

Garrido-Ramos MA, Jamilena M, Lozano R, Rejón CR and Rejón MR (1994) Cloning and characterization of a fish centromeric satellite DNA. Cytogenet Cell Genet 65:233-237.

Garrido-Ramos MA, Jamilena M, Lozano R, Rejón CR and Rejón MR (1995) The Eco RI centromeric satellite DNA of Sparidae family (Pisces, Perciformes) contains a sequence motive common to other vertebrate centromeric satellite DNAs. Cytogenet Cell Genet 71:345-351.

Haaf T, Schmid M, Steinlein C, Galetti Jr PM and Willard HF (1993) Organization and molecular cytogenetics of satellite
DNA family from Hoplias malabaricus (Pisces, Erythrinidae). Chromosome Res 1:77-86.

Haaf T, Warburton PE and Willard HF (1992) Integration of human ALFA-satellite DNA into simian chromosomes: Centromere protein binding and disruption of normal chromosome segregation. Cell 70:681-696.

John B (1988) The biology of heterochromatin. In: Verma RS (ed) Heterochromatin: Molecular and Structural Aspects. Cambridge University Press, New York, pp 1-147.

Johnston FP, Jorgenson KF, Lin CC and Sande JH (1978) Interaction of anthracyclines with DNA and chromosomes. Chromosoma 68:115-129.

Levan A, Fredga K and Sandberg AA (1964) Nomenclature for centromeric position on chromosomes. Hereditas 52:201220.

Lin MS, Comings DE and Alfi OS (1977) Optical studies of the interaction of 4'-6-diamidino-2-phenylindole with DNA and metaphase chromosomes. Chromosoma 60:15-25.

Maistro EL, Oliveira C and Foresti F (1998) Comparative cytogenetic and morphological analysis of Astyanax scabripinnis paranae (Pisces, Characidae, Tetragonopterinae). Genet Mol Biol 21:201-206.

Maistro EL, Oliveira C and Foresti F (2000) Sympatric occurrence of two cytotypes of Astyanax scabripinnis (Characiformes, Characidae). Genet Mol Biol 23:365-369.

Mantovani M, Abel LDS, Mestriner CA and Moreira-Filho O (2000) Accentuated polymorphism of heterochromatin and nucleolar organizer regions in Astyanax scabripinnis (Pisces, Characidae): Tools for understanding karyotypic evolution. Genetica 109:161-168.

Margarido VP and Galetti Jr PM (2000) Amplification of GC-rich heterochromatin in the freshwater fish Leporinus desmotes (Characiformes, Anostomidae). Genet Mol Biol 23:569573.

Mayr B, Kalat M and Rab P (1988) Heterochromatin and band karyotypes in three species of salmonids. Theor Appl Genet 76:45-53.

Mestriner CA, Galetti Jr PM, Valentini SR, Ruiz IRG, Abel LDS, Moreira-Filho O and Camacho JPM (2000) Structural and functional evidence that a B chromosome in the characidae fish Astyanax scabripinnis is an isochromosome. Heredity 85:1-9.

Mizoguchi SMHN and Martins-Santos IC (1998) Cytogenetics and morfometric differences in populations of Astyanax "scabripinnis" (Pisces, Characidae) from Maringá region, PR, Brazil. Genet Mol Biol 21:55-61.

Molina WF, Schmid M and Galetti Jr PM (1998) Heterochromatin and sex chromosomes in the neotropical fish genus Leporinus (Characiformes, Anostomidae). Cytobios 94:141-149.

Moreira-Filho O and Bertollo LAC (1991) Astyanax scabripinnis (Pisces, Characidae): A species complex. Brazil J Genet 14:331-357.

Oliveira C and Wright JM (1998) Molecular cytogenetic analysis of heterochromatin in the chromosomes of tilapia, Oreochromis niloticus (Teleostei: Cichlidae). Chromosome Res 6:205-211.

Oliveira C, Vieira MMR and Foresti F (1998) Elaboração de uma filogenia molecular para Astyanax scabripinnis (Pisces, Characiformes, Characidae). VII Simpósio de Citogenética 
Evolutiva e Aplicada de Peixes Neotropicais, Londrina, Brazil. Abstract A19.

Phillips RB and Reed KM (2000) Localization of repetitive DNAs to zebrafish (Danio rerio) chromosomes by fluorescence in situ hybridization (FISH). Chromosome Res 8:27-35.

Pinkel D, Straume T and Gray JW (1986) Cytogenetic analysis using quantitative, high-sensitivity, fluorescence hybridization. Proc Natl Acad Sci USA 83:2934-2938.

Rab P, Reed KM, León FAP and Phillips RB (1996) A new method for detecting nucleolus organizer regions in fish chromosomes using denaturation and propidium iodide staining. Biotechnic \& Histochemistry 71:157-162.

Reed KM and Phillips RB (1995) Molecular characterization and cytogenetic analysis of highly repeated DNAs of lake trout, Salvelinus namaycush. Chromosoma 104:242-251.

Rossi AR, Crosetti D, Gornung E and Sola L (1996) Cytogenetic analysis of global populations of Mugil cephalus (striped mullet) by different staining techniques and fluorescent in situ hybridization. Heredity 76:77-82.

Saitoh Y and Laemmli UK (1994) Metaphase chromosome structure: Bands arise from a differential folding path of the highly AT-rich scaffold. Cell 76:609-622.

Schmid M (1980) Chromosome banding in Amphibia. IV. Differentiation of GC and AT rich chromosome regions in Anura. Chromosoma 77:83-103.

Schmid M and Guttenbach M (1988) Evolutionary diversity of reverse fluorescence chromosome bands in vertebrates. Chromosoma 97:101-114.

Schweizer D (1976). Reverse fluorescent chromosome banding with chromomicin and DAPI. Chromosoma 58:307-324.

Schweizer D and Loidl J (1987). A model for heterochromatin dispersion and the evolution of $\mathrm{C}$ band patterns. Chromosomes Today 9:61-74

Schweizer D, Ambros P and Andrle M (1978) Modification of DAPI banding on human chromosomes by prestaining with a DNA-binding oligopeptide antibiotic, distamycin A. Expl Cell Res 111:327-332.

Sola L and Gornung E (2001) Classical and molecular cytogenetics of the zebrafish, Danio rerio (Cyprinidae, Cypriniformes): An overview. Genetica 111(1-3):397-412.

Sola L, De Innocentiis S, Gornung E, Papalia S, Rossi AR, Marino G, De Marco P and Cataudella S (2000) Cytogenetic analysis of Epinephenus marginatus (Pisces, Serranidae), with the chromosome localization of the 18S and 5S rRNA genes and of the (TTAGGG) $)_{\mathrm{n}}$ telomeric sequence. Marine Biol 137:47-51.

Sola L, Rossi AR, Iaselli V, Rasch EM and Monaco PJ (1992) Cytogenetics of bisexual/unisexual species of Poecilia. II. Analysis of heterochromatin and nucleolar organizer regions in Poecilia mexicana by C-banding and DAPI, quinacrine, chromomycin $\mathrm{A}_{3}$ and silver staining. Cytogenet Cell Genet 60:229-235.

Souza IL and Moreira-Filho O (1995) Cytogenetic diversity in the Astyanax scabripinnis species complex (Pisces, Characidae). I. Allopatric distribution in a small stream. Cytologia 60:1-11.

Souza IL, Moreira-Filho O and Galetti Jr PM (1996) Heterochromatin differentiations in the characid fish Astyanax scabripinnis. Brazil J Genet 19:405-410.

Sumner AT (1972) A simple technique for demonstrating centromeric heterochromatin. Expl Cell Res 75:304-306.

Sumner AT (1990) Chromosome banding. Unwin Hyman Inc., London, 434 pp.

Verma RS (1988) Heterochromatin: Molecular and structural aspects. Cambridge University Press, New York, 320.

Zimmer CH, Reinert KE, Luck G, Wähnert U, Löber $\mathrm{G}$ and Thrum H (1971) Interaction of the oligopeptide antibiotics netropsin and distamicin A with nuclei acids. J Mol Biol 58:329-348.

Associate Editor: Fausto Foresti 